\title{
Effect of magnetic stirring, grain modification and refinement on the solidification structure of an A356 aluminum alloy
}

Óscar Bustos ${ }^{1}$, Rodrigo Allende ${ }^{1}$, Ricardo Leiva ${ }^{1}$, Christian Sánchez ${ }^{1}$

\author{
${ }^{1}$ Universidad de Santiago de Chile, Departamento de Ingeniería Metalúrgica, Facultad de Ingeniería, Av. Lib. Bernardo \\ O'Higgins 3363, Santiago, Chile \\ e-mail: oscar.bustos@usach.cl,rodrigo.allende@usach.cl,rleivaillanes@gmail.com,christian.sanchez@usach.cl
}

\begin{abstract}
The effect of the application of forced convection during the continuous solidification of Al-Si alloys has been presented in this work. The investigation has been made on the hypothesis that as an alloy solidifies under the action of a rotating magnetic field, a nondendritic casting structure would be obtained. The Al-Si alloy has been studied in its three different states (original, modified, and modified with a grain refiner), using a magnetic stirring equipment with permanent magnets, a device that has allowed the study of the effect of the rotational speed (degree of stirring) on the micro- and macro- solidification structure, as well as on the material's mechanical properties. With the purpose of validating the hypothesis, different analyses and tests have been carried out, such as thermal analysis of the solidification process, micro- and macrostructural analysis, and hardness measurements for the different process conditions studied. The results have shown that magnetic stirring affects the cooling curves, expanding the solidification range. A microstructural evolution of the alloys has also been observed, from a $100 \%$ dendritic structure to a mature rosette type structure, in addition to a notable decreasing of grain size, which results in the improvement of the material's mechanical behavior.
\end{abstract}

Keywords: Grain Refinement, forced convection, solidification, Al-Si.

\section{INTRODUCTION}

It is known that aluminum and its alloys make up more than $80 \%$ of the production of nonferrous alloys. Therefore, it is necessary to look for methods that allow getting casting materials that offer the best possible performance, and in this search, technologies have been adapted for this purpose. Getting parts by casting alloys directly in a mold is, in general, an advantageous process when dealing with complex shape parts which are meant to be mass-produced, or very large parts. However, these products have a typical solidification structure that sometimes decreases their mechanical performance. Casters must deal with segregation [1, 2], porosity caused by shrinkage during the solidification [1], and the trapping of gases [3]. In order to deal with these problems and obtain pieces with good mechanical service, they has been developed methods like stirring the melt during the solidification (semisolid state) $[4,5]$ or the addition of some alloying elements to modify the shape, size, and distribution of the phases in microstructure.

\subsection{Magnetic stirring}

The use of magnetic fields during the solidification of metals dates back to the 1930s (their advantage is the lack of contact between the stirrer and the liquid metal). Magnetic stirring takes place due to the Lorentz force generated by an alternating inductor [6 - 8]. The magnetic stirrer is designed deliberately to produce convection in the liquid near the solidification front, through the application of low frequency magnetic fields to allow the Lorentz force acts deeply in the liquid metal. Two types of electromagnetic stirrers are commonly used: the linear stirrer and the rotatory stirrer. A linear stirrer operates basically as an induction furnace. This consists of a battery of coils around the molten metal to create a primary motion that recirculates in the melting direction. A rotary stirrer is basically an electric motor which uses a rotary magnetic field to produce 
a spiral motion in the liquid. These types of stirring can be applied individually or combined, and the stirring can be applied in different stages of the solidification.

The effect of the stirring over the microstructure (decrease of micro- and macro-segregation), mechanical properties and favoring of the shaping and/or mechanizing processes has been studied for various materials [9 - 14]. This improvement, which is associated with the refining of the casting structure, is due to the dendritic fragmentation produced by the shearing stress caused by the liquid's convection ahead of the solidification front promoted by the magnetic stirring. However, there still is no full agreement as to how dendritic fragmentation takes place.

There are several theories that try to explain dendritic fragmentation, among them those proposed by FLEMINGS in 1991 [6], which include fragmentation of the base of the dendritic branches caused by the high shear stress produced by magnetic stirring or by the remelting of the dendritic roots of the branches, caused by dendritic maturing. VOGEL et al. [7] in their book Solidification and Casting of Metals of 1979 propose a dendritic fragmentation mechanism that involves bending (caused by the shear stress) of the dendritic branches, giving rise to oriented dislocations forming a sort of low angle grain limit, which after bending more than 20 degrees is replaced by a liquid line (energetically more favorable), fracturing the dendrite as shown in Figure 1.

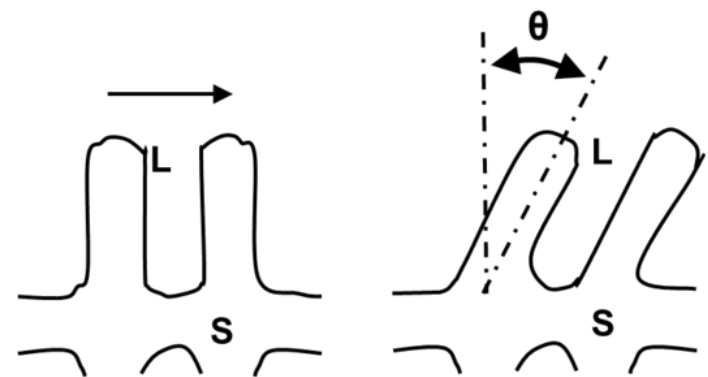

(a)

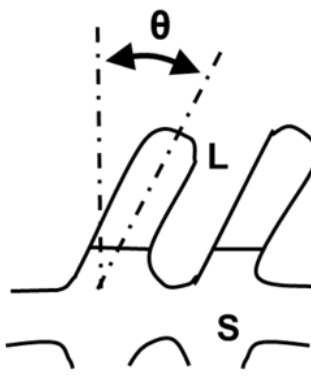

(c)

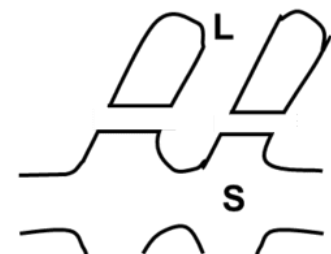

(d)

Figure 1: Dendritic fragmentation according to VOGEL et al. [7]

Finally, using an ultrasonic cavitation technique [15], it had seen that the typical dendritic fragmentation mechanisms occur by fatigue, collapse, or fracture by bending, validating the first postulate of Fleming and that of Vogel et al., including fatigue as responsible for this phenomenon.

The fragments separated from the dendrites initially do not have a spherical shape, and under the proper conditions they can be the site of new growth with a dendrite shape. In general, the structure of alloys subjected to processes in semisolid state (magnetic stirring) may be modified, evolving from a dendritic one to rosettes that still contain liquid trapped between their arms, and eventually spherical particles, as shown in the sequence of Figure 2. 
(a)

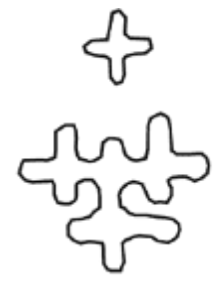

(c)

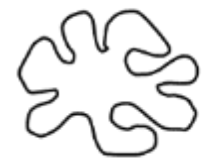

(d)

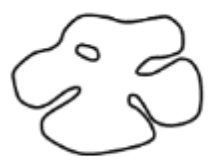

(e)

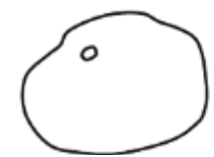

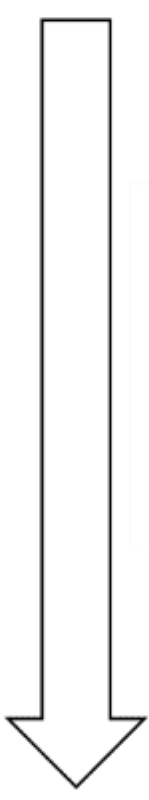

\section{Increased stirring rate}

\section{Decreased cooling rate}

Figure 2: Evolution of the structure in the semisolid state.

\subsection{Modification and refinement of the microstructure}

Hipoeutectic Al-Si alloys as A356, once solidified, have basically two microconstituents: one with low resistance and ductile, primary $\alpha-\mathrm{Al}$, and an eutectic that consists of $\alpha-\mathrm{Al}$ and Si needles (with high hardness and fragile), where the $\alpha-\mathrm{Al}$ acts as a matrix for the Si phase. This eutectic has the particularity of being irregular, because it incorporates the characteristics of the metals through $\mathrm{Al}$ and of a nonmetal like $\mathrm{Si}$, so its mechanical resistance is directly related to the shape, size, and distribution of $\mathrm{Si}[16,17]$.

In the unmodified structures the $\mathrm{Si}$ is distributed as plates with tension accumulating sharp edges, and its fracture limits the ductility of the alloy, at the same time providing resistance to the matrix [18]. However, this is not a limitation because the distribution of the $\mathrm{Si}$ in the $\alpha$-Al matrix can be modified by the addition of elements like $\mathrm{Na}$ and $\mathrm{Sr}$, going from a platelike distribution to a fibrous [19, 20], as shown in Figure 3.
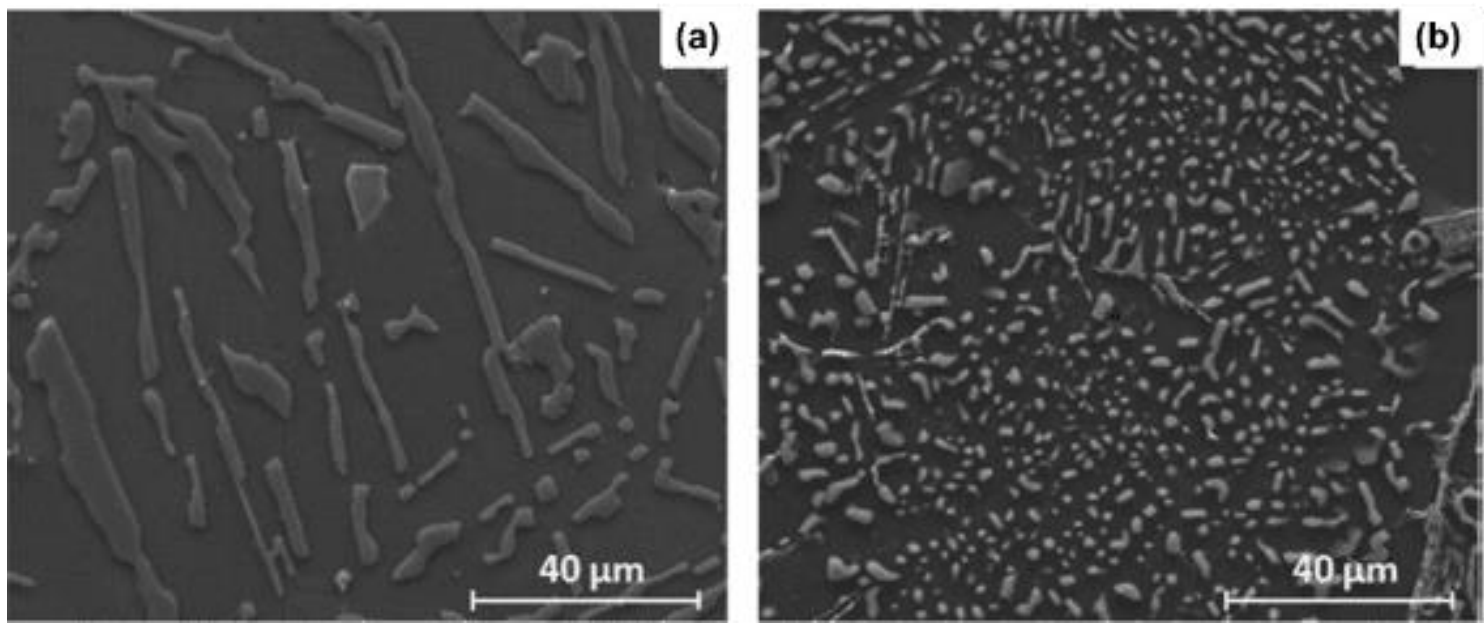

Figure 3: Eutectic Al-Si. (a) unmodified and (b) modified.

On the other hand, it has been found that in those structures that have not been modified there is a clear relation between the size of the Si particles and the mechanical properties, namely, when the Si particles are small, then the benefits of the modified structures on the mechanical properties can be seen [21]. Studies on the effect of grain refinement $[22,23]$ in casting alloys indicate that a grain size decrease gives rise to great benefits, such as the improvement and homogeneity of the mechanical properties on the part, the uni- 
form distribution of second phases, small scale gaseous microporosity, decreased porosity by shrinkage, improvement of the material's capacity to achieve a uniform anodized surface, extension of fatigue life.

In general, grain refinement of aluminum-based alloys is carried out by the addition of alloys of the $\mathrm{Al}-\mathrm{Ti}-\mathrm{B}$ type. The most widely used is $\mathrm{Al}-5 \% \mathrm{Ti}-1 \% \mathrm{~B}$. The addition ratio is close to $1 \mathrm{~kg} / \mathrm{ton}$, delivering $\mathrm{Ti}$ and $\mathrm{B}$ additions of $500 \mathrm{ppm}$ and $100 \mathrm{ppm}$, respectively.

\section{EXPERIMENTAL PROCEDURE}

The raw material used in the experiments is an A356 aluminum-silicon-magnesium alloy in three states, i.e., (A) original alloy, (B) Sr modified alloy, and (C) Sr modified and refined with Al-Ti-B alloy, whose chemical composition was determined by optical emission spectrometry according to ASTM E607-02 [24] and is presented in Table 1.

Table 1: Chemical composition of the alloys used.

\begin{tabular}{ccccccccc}
\hline ALLOY & \%SI & \%FE & \%MG & \%CU & \%SR & \%TI & \%B & \%AL \\
\hline A & 7.511 & 0.260 & 0.281 & 0.008 & - & 0.001 & - & Balance \\
\hline B & 7.210 & 0.277 & 0.266 & 0.009 & 0.020 & 0.004 & 0.001 & Balance. \\
\hline C & 7.310 & 0.279 & 0.233 & 0.007 & 0.022 & 0.044 & 0.009 & Balance \\
\hline
\end{tabular}

Each of the alloys studied was solidified under different degrees of magnetic stirring, for which the samples were cast in a crucible placed over a magnetic stirring apparatus (Figure 4a) which basically consists of:

- A cylindrical frame in which there are three pairs of permanent magnets equidistant from one another (Figure 4b)

- Coupling components to an alternating current motor.

- A $120 \mathrm{~mm}$ long and $50 \mathrm{~mm}$ outer diameter crucible made of AISI 316L stainless steel. The tube is lined on the inside with high alumina refractory concrete that shapes the crucible's cavity (Figure $4 c)$
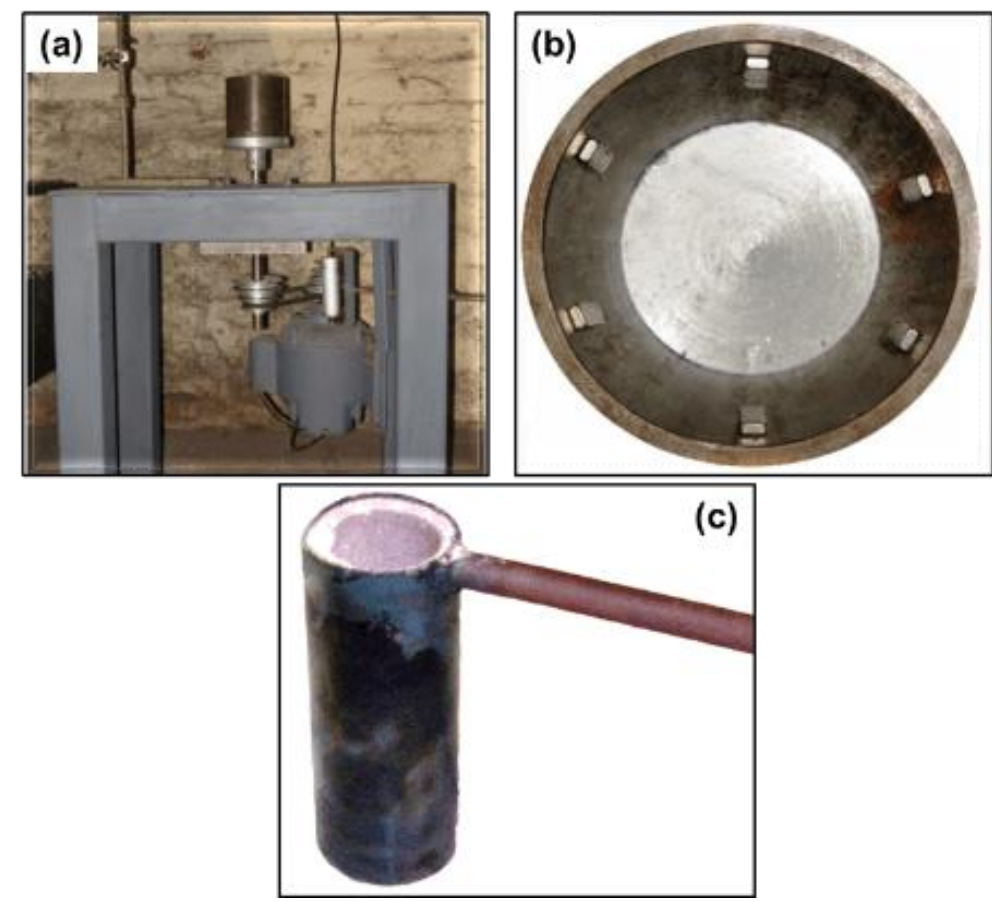

Figure 4: Equipment and materials used. (a) magnetic stirring equipment; (b) turning frame ;(c) crucible. 
The equipment can have three different rotational speeds ( $880 \mathrm{rpm}, 1460 \mathrm{rpm}$, and $2360 \mathrm{rpm})$. Each alloy was first melted in a crucible whose frame did not turn, providing the sample designated with subscript 0. After it solidified, the same procedure was followed to provide the samples with subscripts 1, 2, and 3, corresponding to frame turning speeds of $880 \mathrm{rpm}, 1460 \mathrm{rpm}$, and $2360 \mathrm{rpm}$, respectively. The distribution of alloys and their stirring speeds are presented in Table 2. For example, sample $\mathbf{B}_{2}$ corresponds to the modified alloy subjected to magnetic stirring with the frame rotational at $1460 \mathrm{rpm}$.

Table 2: Sample identification.

\begin{tabular}{cccc}
\hline TURNING SPEED & \multicolumn{3}{c}{ ALLOY } \\
\cline { 2 - 4 }$($ RPM) & A & B & C \\
\hline 0 & A0 & B0 & C0 \\
\hline 880 & A1 & B1 & C1 \\
\hline 1460 & A2 & B2 & C2 \\
\hline 2360 & A3 & B3 & C3 \\
\hline
\end{tabular}

For each of the samples obtained, the evolution of temperature over time was measured during their solidification, and cooling curves were drawn, obtained to temperatures characteristic of solidification, which are recalescence due to the solidification of primary aluminum, beginning of the solidification of the eutectic micro constituent, and recalescence due to the solidification of eutectic aluminum-silicon. A schematic of the assembly is shown in Figure 5.

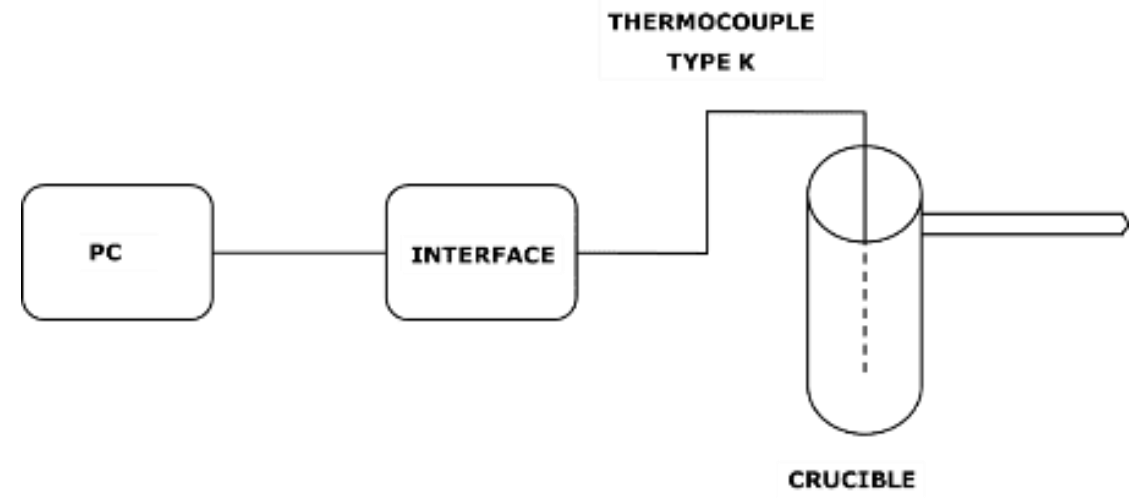

Figure 5: Assembly used for obtaining the cooling curves.

Once solidified, the samples were cut longitudinally with a cooled abrasive cutting disc, and they were prepared for the macrographic analysis to reveal their casting structure, etching them with cupric chloride. After getting their structures, the samples were prepared for metallographic analysis according to ASTM E317 [25], and then they were etched with Keller's reagent, revealing their microstructure. The AlFeSi-type intermetallic compounds ( $\alpha$ and $\beta$ ) were characterized with the help of a Philips scanning electron microscope (SEM), model XL-30, owned by the Center for Technical Studies and Research in Guipúzcoa, CEIT, San Sebastian, Spain, and its chemical analysis by means of a micro probe (X-ray dispersive energy, EDAX).Furthermore, the Brinell hardness of the samples was measured according to ASTM E10-17 [26].

\section{RESULTS AND DISCUSSION}

\subsection{Thermal Analysis}

Figure 6 shows the cooling curve obtained for $A_{0}$ sample (blue curve). Its critical temperatures relative to the recalescencies were obtained by the determination of the maximum of the temperature rate of change $(\mathrm{dT} / \mathrm{dt}$, green curve) and the beginning of the solidification of the eutectic through the consideration of the second derivative of the temperature over time $\left(\mathrm{d}^{2} \mathrm{~T} / \mathrm{dt}^{2}\right.$, orange curve). The shape of the curves and obtaining their 
characteristic temperatures is similar for the other samples. The characteristic temperatures for all the samples are shown in Table 3.

Observing separately each one of the alloys and comparing their characteristic temperatures obtained for the states without stirring and with maximum stirring, the increase of nearly $3{ }^{\circ} \mathrm{C}$ of the temperature related to the recalescence due to the solidification of $\alpha$-Al because of the stirring can be mentioned, while the temperatures related to the eutectic reaction decrease by about $3{ }^{\circ} \mathrm{C}$. This is mainly caused because stirring provides better conditions for nucleation, and in the case of the eutectic reaction it produces a greater homogenization in the liquid, and this decreases the constitutional supercooling, which in turn generates a thermal supercooling, facilitating nucleation. In the literature stirring has been mentioned as a controlled nucleation mechanism [27], because favors nucleation by raising the initial transformation temperature from liquid to $\alpha$ $\mathrm{Al}$, and as the constitutional supercooling decreases and a thermal one is generated (together with the effect of dispersing the sheared dendritic fragments), would promote the development of nondendritic structures tending to an equiaxial primary phase morphology.

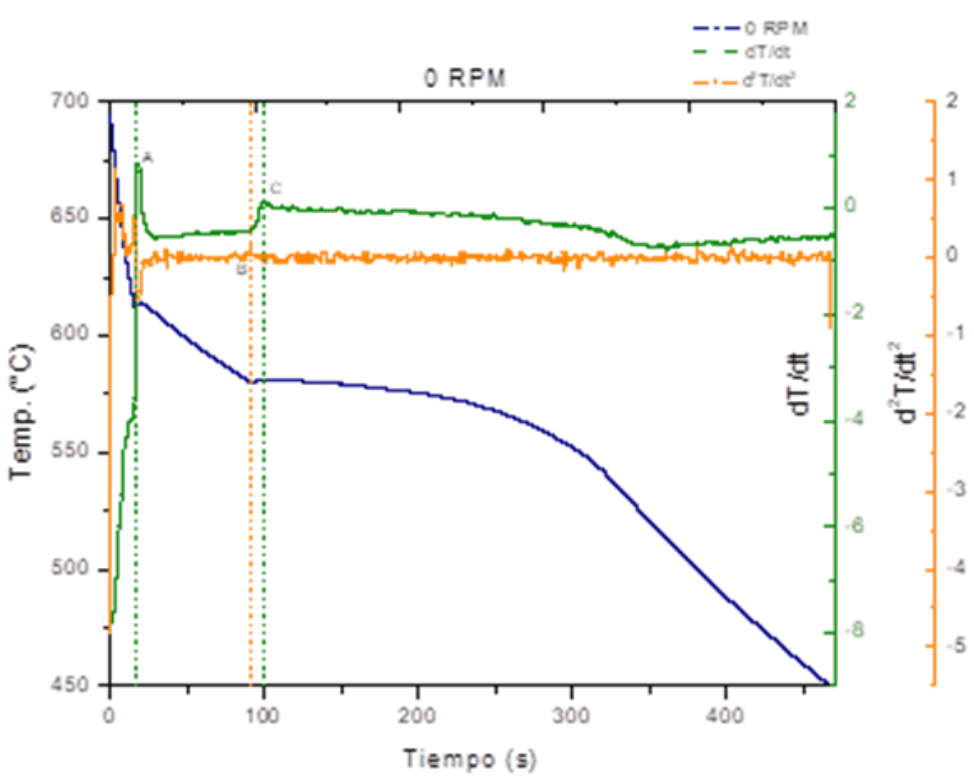

Figure 6: Cooling curve and determination of the characteristic solidification temperatures. Sample $\mathrm{A}_{0}$

Table 3: Characteristic temperatures for samples A0 and A3.

\begin{tabular}{cccccccc}
\hline CHARACTERISTIC TEMPERATURE & A0 & A3 & B0 & B3 & C0 & C3 \\
\hline $\begin{array}{c}\text { Recalescence due to the } \\
\text { solidification of } \alpha \text {-Al }\end{array}$ & $606.2{ }^{\circ} \mathrm{C}$ & $608.9{ }^{\circ} \mathrm{C}$ & $609.6{ }^{\circ} \mathrm{C}$ & $611.9{ }^{\circ} \mathrm{C}$ & $613.3{ }^{\circ} \mathrm{C}$ & $616.1^{\circ} \mathrm{C}$ \\
\hline $\begin{array}{c}\text { Beginning of solidification } \\
\text { of the eutectic phase }\end{array}$ & $584.3^{\circ} \mathrm{C}$ & $581.6{ }^{\circ} \mathrm{C}$ & $579.8^{\circ} \mathrm{C}$ & $577.6{ }^{\circ} \mathrm{C}$ & $580.7{ }^{\circ} \mathrm{C}$ & $578.6{ }^{\circ} \mathrm{C}$ \\
\hline $\begin{array}{c}\text { Recalescence due to the solidification } \\
\text { of Al-Si eutectic }\end{array}$ & $583.3^{\circ} \mathrm{C}$ & $579.9{ }^{\circ} \mathrm{C}$ & $576.7{ }^{\circ} \mathrm{C}$ & $574.3{ }^{\circ} \mathrm{C}$ & $580.3{ }^{\circ} \mathrm{C}$ & $578.3{ }^{\circ} \mathrm{C}$ \\
\hline
\end{tabular}

If only the characteristic temperatures of the unstirred samples are compared, a recalescence temperature rise due to the solidification of $\alpha-\mathrm{Al}$ is seen when incorporating $\mathrm{Al}-\mathrm{Ti}-\mathrm{B}$ to the chemical composition, because the $\mathrm{Ti}$ and $\mathrm{B}$ compounds act as preferential nucleation sites, catalyzing the solidification reaction of the primary phase, and therefore decreasing the undercooling required for it to take place [22, 23]. In sample $\mathrm{B}$, the addition of $\mathrm{Sr}$ has a smaller effect on the solidification of the primary phase, however the characteristic temperatures related to the development of the eutectic decrease due to its modifying effect too [17]. 
If temperatures of the beginning of the solidification of the eutectic and the recalescence due to solidification are considered, for the $\mathrm{C}_{0}$ alloy, it is seen that the obtained data agree with what is discussed by KASHYAP et al. [28], due to the effect of grain refinement on the heat extraction. Since there is a large amount of $\alpha-\mathrm{Al}$ crystals, there is a great availability of heat sinks that extract the heat of the eutectic transformation faster, and this in turn decreases the recalescence.

\subsection{Macrographic Analysis}

Figures 7, 8, and 9 present images related to macrographic analysis of the original samples, modified with $\mathrm{Sr}$, and modified with $\mathrm{Sr}$ and refined with Al-Ti-B, respectively, at different stirring speeds. Furthermore, the upper right corner of each image shows the grain size obtained from the linear intersection as described in the ASTM E112-13 standard [28].

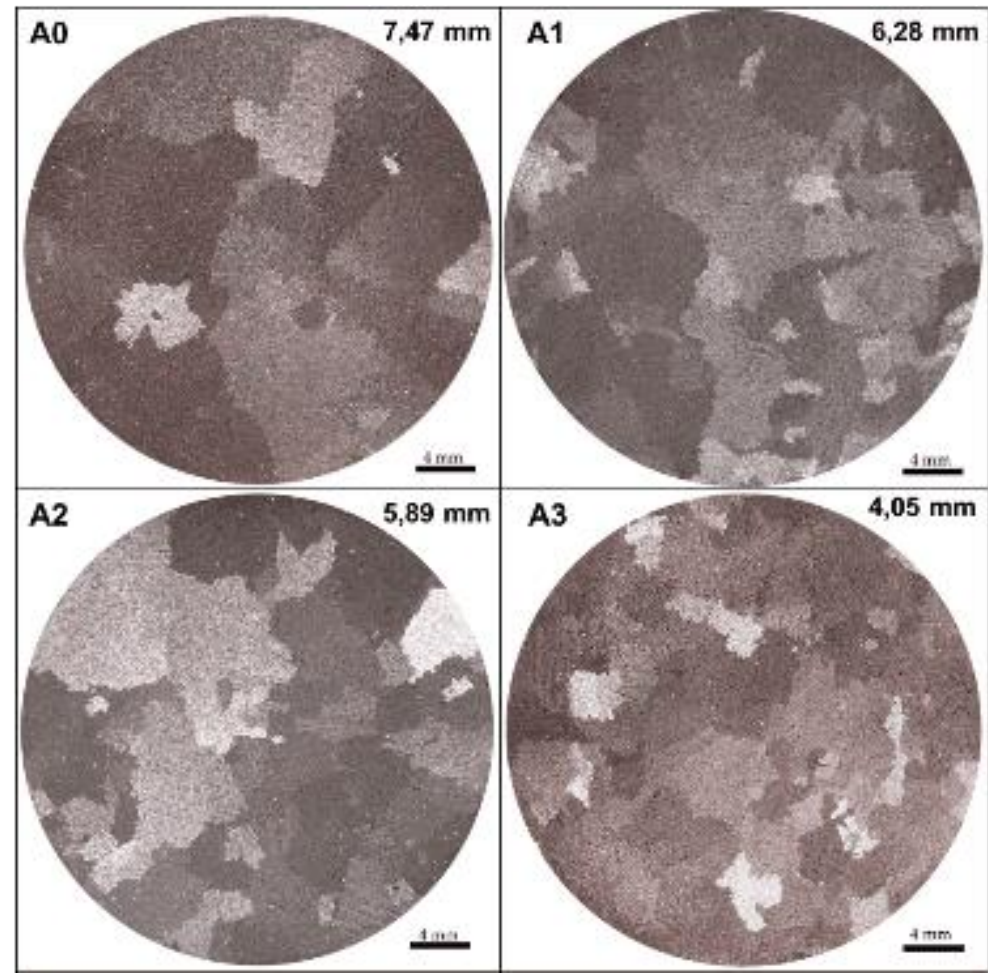

Figure 7: Macrographs and grain sizes of the samples. Original alloy. 


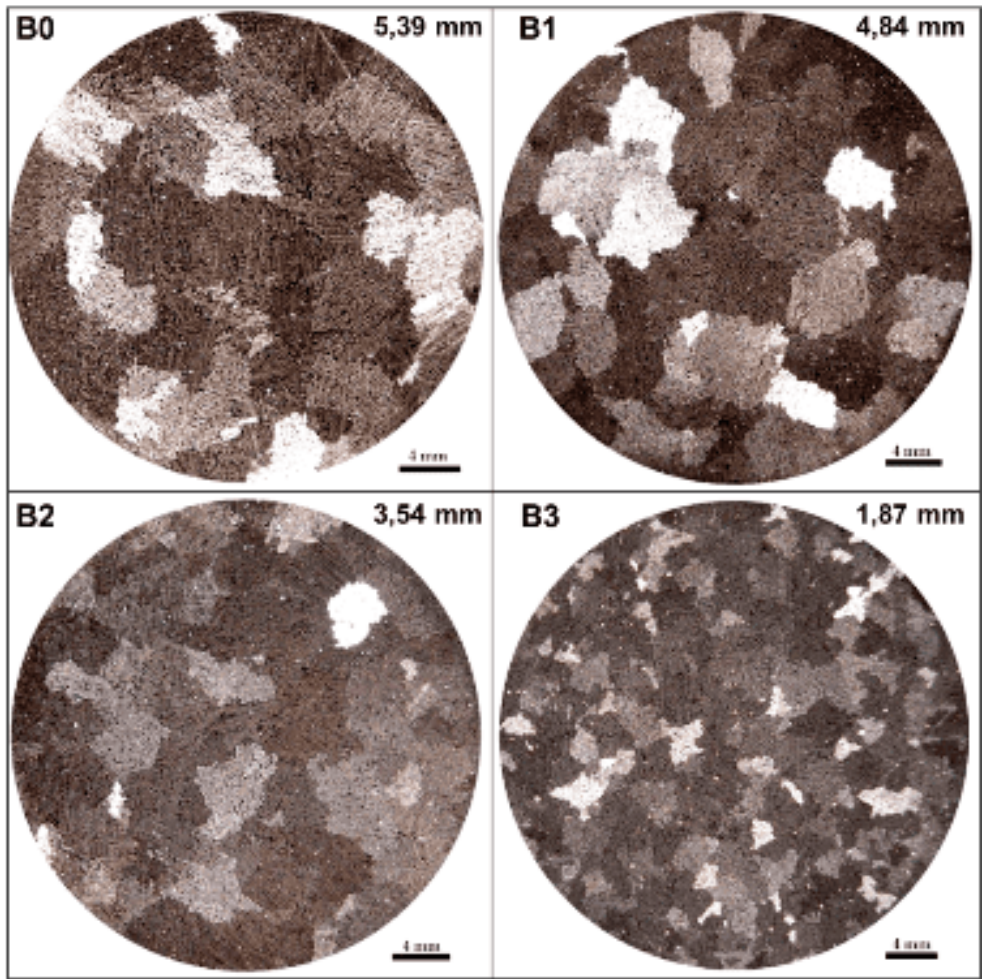

Figure 8: Macrographs and grain sizes of the samples. Alloy modified with Sr.

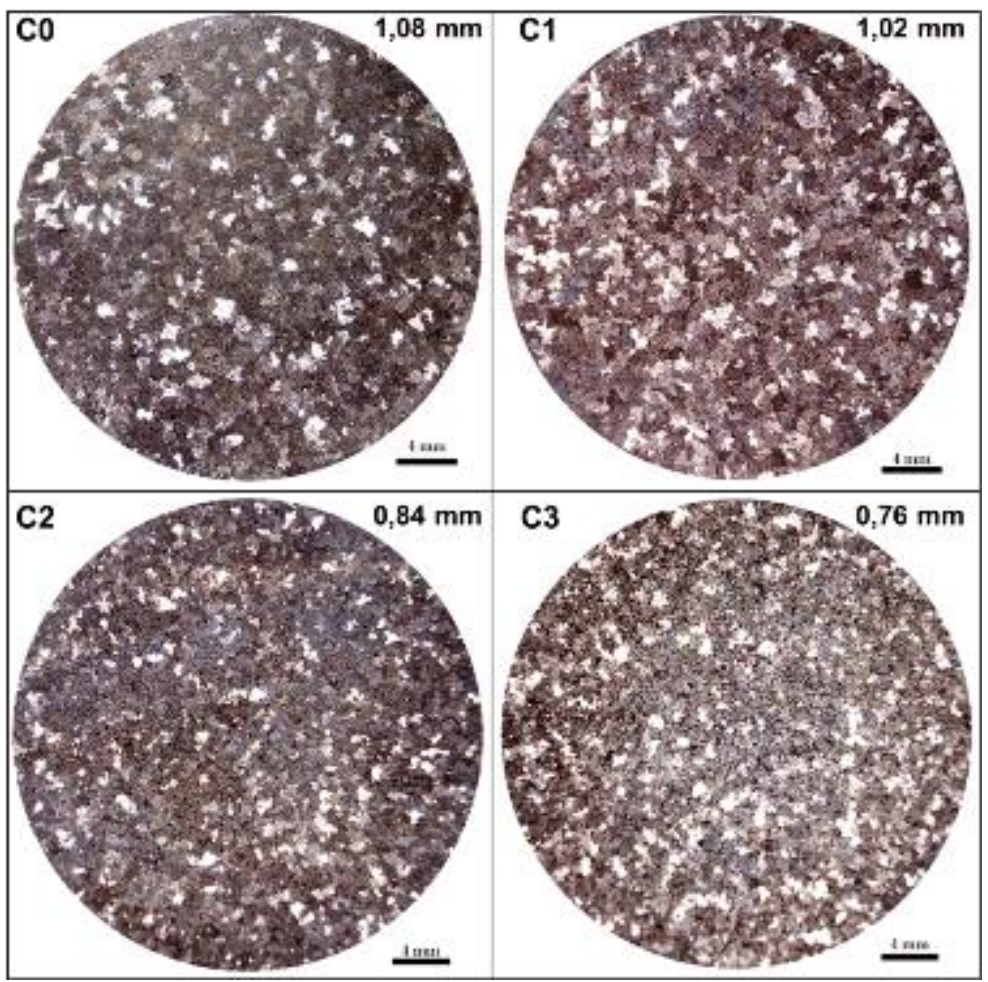

Figure 9: Macrographs and grain sizes of the samples. Alloy modified with $\mathrm{Sr}$ and refined with Al-Ti-B. 
Additionally, Figure 10 presents a comparative graph of the grain sizes obtained for all the samples.

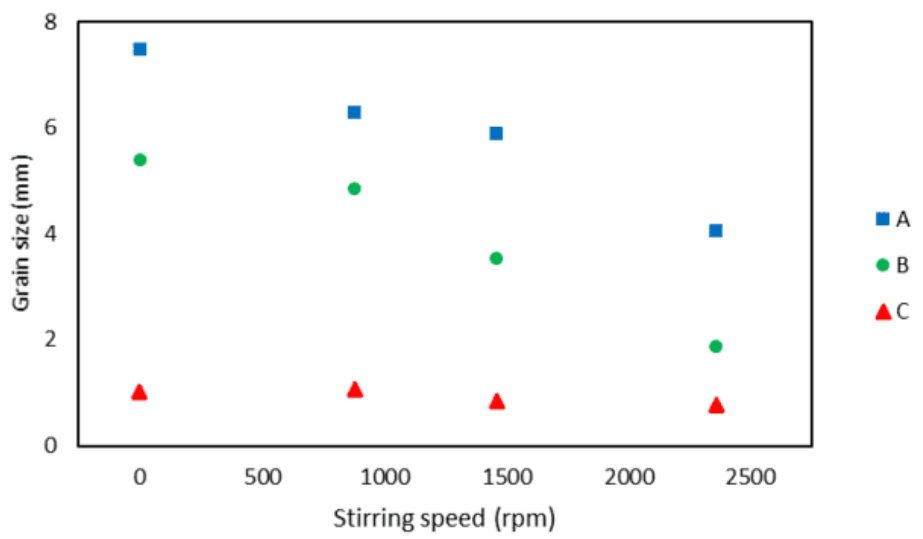

Figure 10: Evolution of grain size with respect to the degree of magnetic stirring and the addition of alloying elements.

Figures 7 and 8 show that as the degree of stirring increases, a smaller grain size is obtained, in agreement with this was discussed in the previous section, and it was also seen that in the absence of stirring (samples $\mathrm{A}_{0}$ and $\mathrm{B}_{0}$ ) there is a tendency to develop a columnar dendritic structure, which tends to structures close to equiaxiality as the stirring speed increases. Figure 9 also shows a decrease of grain size caused by stirring, whose influence seems to be marginal in view of the decreased size caused by the addition of refining and modifying elements.

On the other hand, the columnar grains that appear in the unstirred original alloy evolve toward equiaxial arrangements by incorporating $\mathrm{Sr}$ and $\mathrm{Al}-\mathrm{Ti}-\mathrm{B}$ to their composition. The effect of $\mathrm{Sr}$ on the modification of the Si has been studied extensively [19, 20], and in agreement with the results obtained, it also has a grain refining effect of the primary $\alpha$ - $\mathrm{Al}$, suggesting the idea that $\mathrm{Sr}$ can form high melting point compounds that act as elements that favor the nucleation of the primary phase [27]. According to the relation of HallPetch for grain size and mechanical properties, it would be expected that sample $\mathrm{C}$ should provide higher tensile properties and hardness $[29,30]$.

\subsection{Micrographic analysis}

Figures 11, 12, and 13 present micrographs of originals, modified with $\mathrm{Sr}$, and modified with $\mathrm{Sr}$ and refined with Al-Ti-B samples, respectively, with different degrees of stirring. Furthermore, in the upper right corner of each image the corresponding Brinell hardness is given. The figures show the microstructure typical of these kinds of materials, which consists of an $\alpha$-Al matrix (clear phase), with the presence of eutectic (dark constituent), in agreement with what was described in section 1. Additionally, Figure 15 shows an image obtained by SEM and optical microscope showing the different intermetallic phases that make up the microstructure of the A0 alloy. The presence of Eutectic $\mathrm{Si}, \mathrm{Mg}_{2} \mathrm{Si}, \alpha \mathrm{AlFeSi}, \beta \mathrm{AlFeSi}$ and primary $\mathrm{Al}$ has been observed using light microscopy and SEM. $\mathrm{Mg}_{2} \mathrm{Si}$ compound is easy to identify metallographically, since Keller's reagent stains it light gray, differentiating it from the dark gray that characterizes eutectic silicon. The criteria applied to discriminate between $\alpha \mathrm{AlFeSi}$ and $\beta \mathrm{AlFeSi}$ phases in particle recognition were:

- Particle morphology: since the beta phase has an acicular or plate appearance, and the alpha phase has a "Chinese script" or globular appearance. Thus, the beta phase will present a high aspect ratio and form factor, where the aspect ratio is defined as: (dmax / dmin), and the shape factor.

- Light intensity (SEM, backscattering): Since in SEM, the alpha phase is bright and the beta phase opaque.

- Fe / Si ratio (measured by EDAX): Since the beta phase presents a ratio close to 1, the alpha phase, on the other hand, presents a ratio close to 2 , although much higher ratios for the alpha phase have been reported in the literature. 


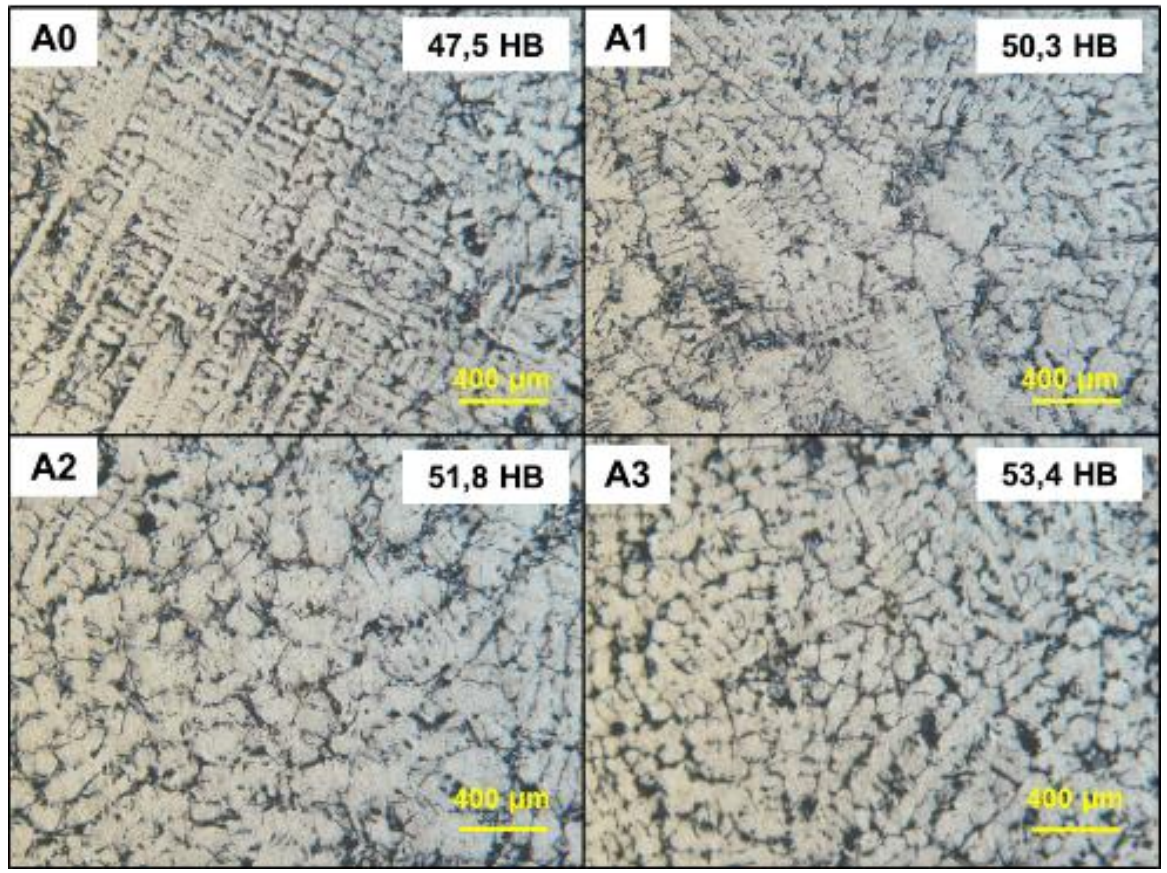

Figure 11: Micrographs of the obtained samples. original alloy.

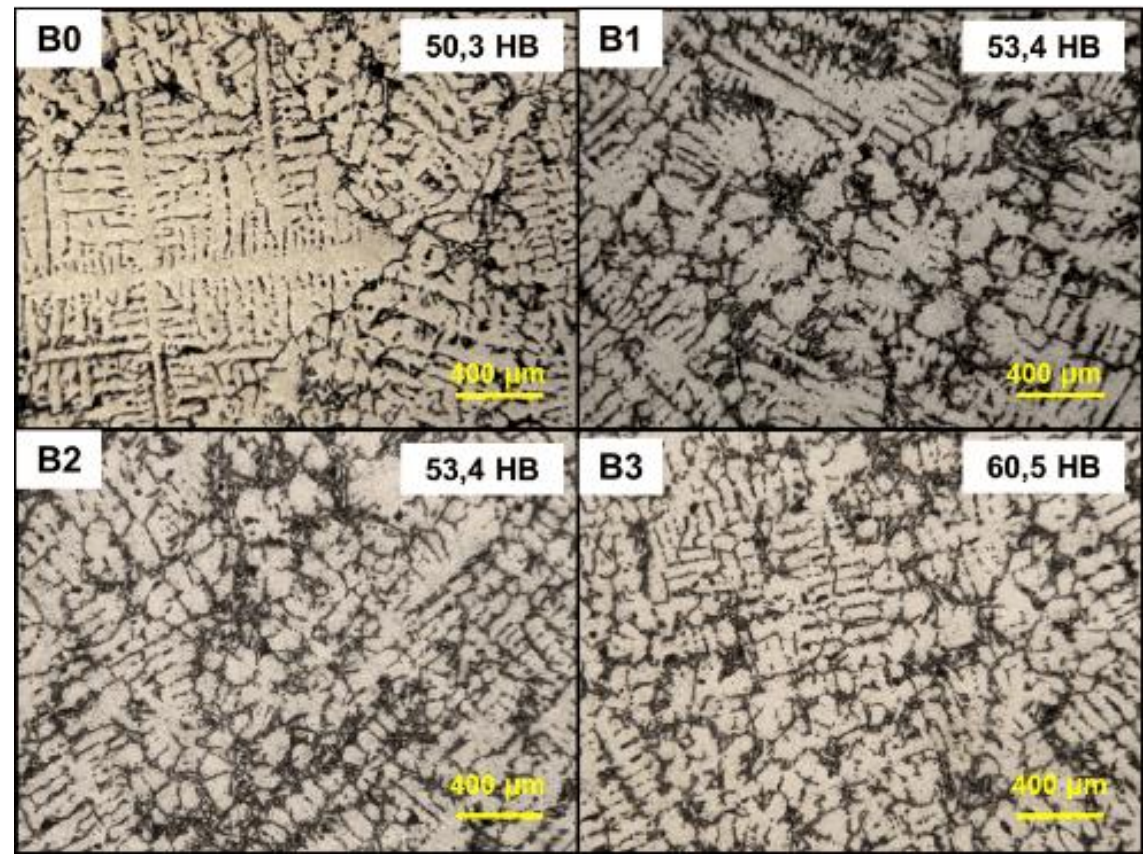

Figure 12: Micrographs of the obtained samples. Alloy modified with Sr. 


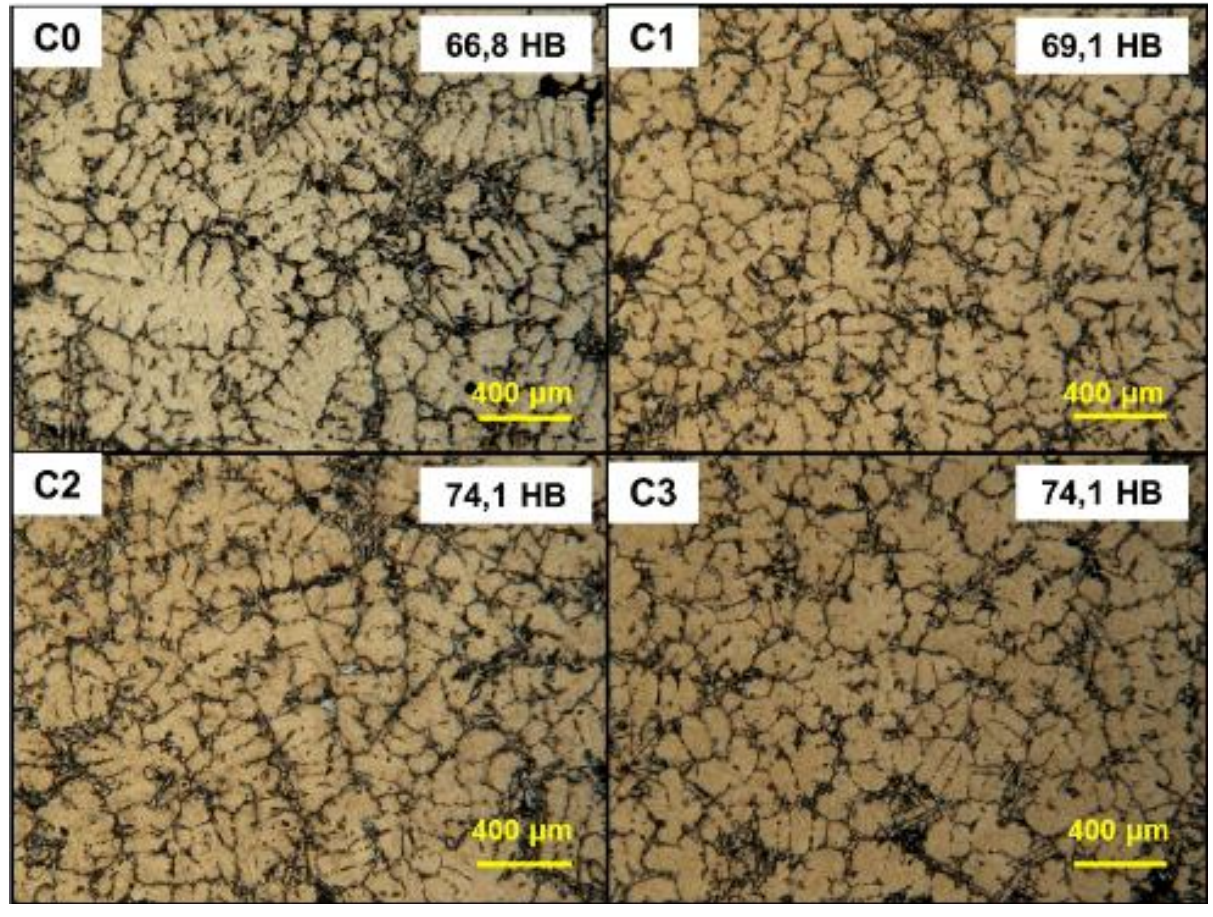

Figure 13: Micrographs of the obtained samples. Alloy modified with $\mathrm{Sr}$ and refined with Al-Ti-B.

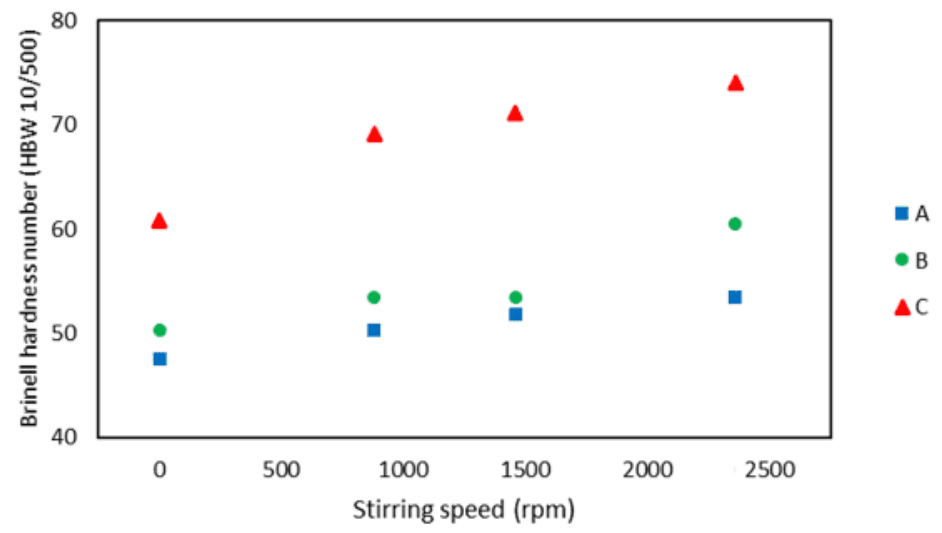

Figure 14: Relationship between Hardness and degree of magnetic stirring and the addition of alloying elements. 


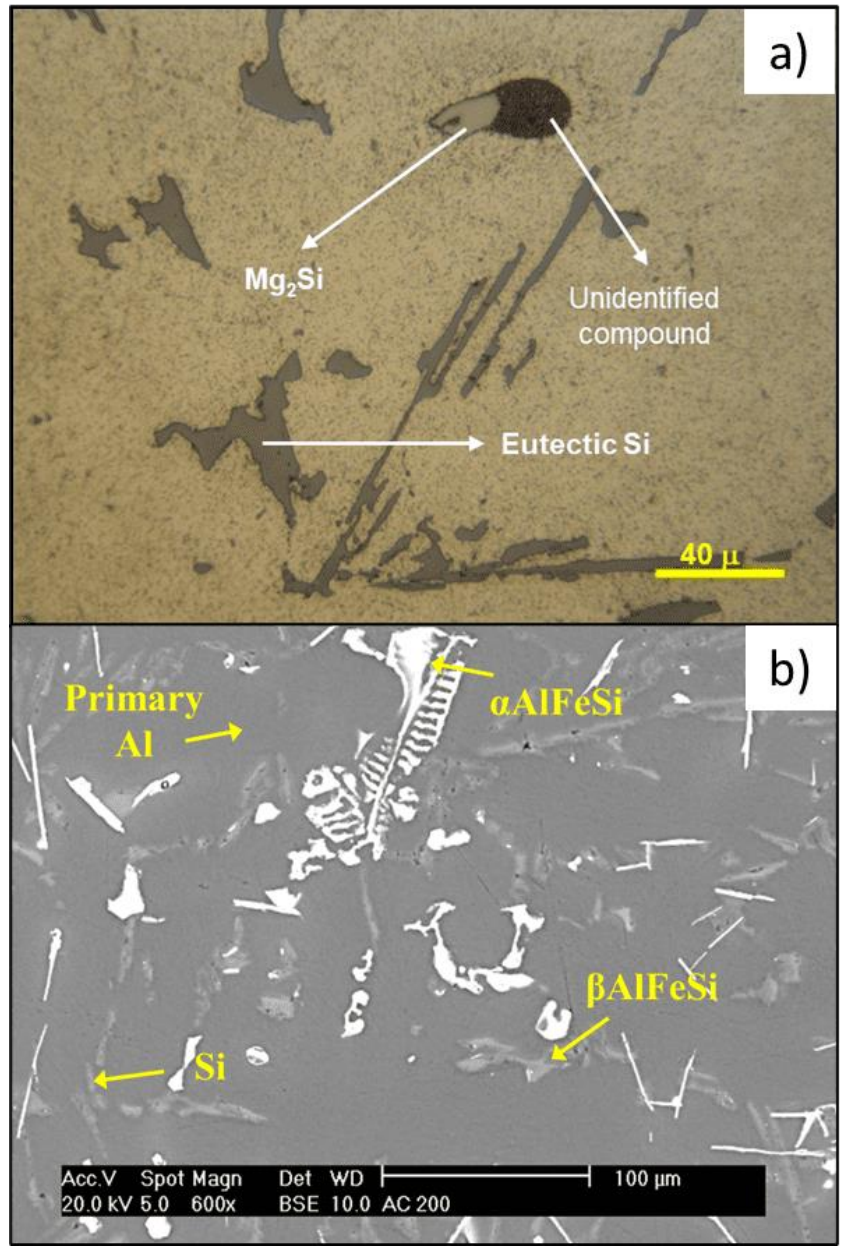

Figure 15:. Intermetallic compounds present in A0 alloy. a) OM image. b) SEM image .

Figures 11 and 12 shown clearly the evolution of the structures from a dendritic $\left(\mathrm{A}_{0}\right.$ and $\left.\mathrm{B}_{0}\right)$ to mature rosettes $\left(A_{3}\right.$ and $\left.B_{3}\right)$ caused by the stirring. On the other hand, if we compare the structures of the different states of the alloy at the same degree of stirring, the same above observation is seen, but as a result of its incorporation of grain refining elements that promote the development of structures that tend to have spherical shapes. The above effect can be visualized also in Figure 16, which presents the shape factor (SF) for each of the studied samples, going from greater than 5 for sample $\mathrm{A}_{0}$, to one close to 1 for the sample modified and refined with maximum stirring $\left(\mathrm{C}_{3}\right)$.

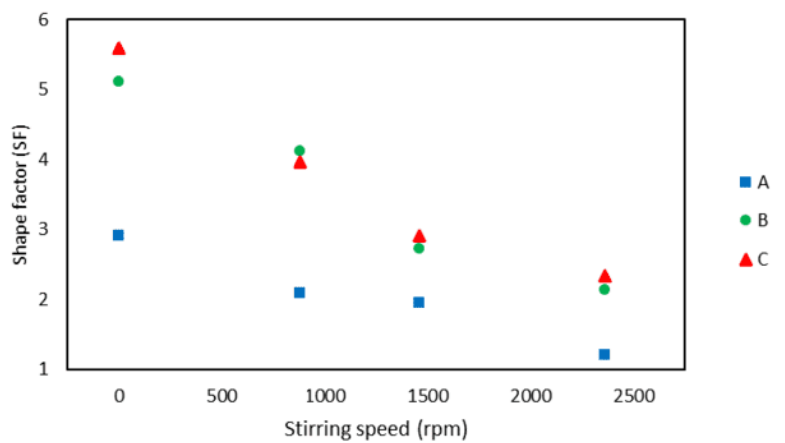

Figure 16: Shape factor of the structure as a function of the degree of stirring. 
Surface area (A), which is related to the degree of roundness; the closer it is to 1, the grater will be its closeness to a sphere. The SF relation is presented in Equation 1.

$\mathrm{SF}=\frac{\mathrm{p}^{2}}{4 \pi \mathrm{A}}$

Figure 17 shows the secondary dendritic arms spacing (SDAS) for the samples. This can be explained by magnetic stirring. The solute accumulated in the liquid in front of the solid / liquid interface will be removed by the convective flow resulting in a higher solute gradient and greater constitutional supercooling, this causes a marked reduction in SDAS relative to the solidified structure without stirring (for lowest stirring speed). As solidification proceeds, the number of dendritic branches that will be fragmented increases by increasing interaction between them. The dendritic fragments that have been initially separated are not spheroidal and if conditions are favorable they will continue to grow as dendrites. However, ripening processes obtained to the reduction of the surface area will operate and the regions of high curvature will be eliminated or reduced by diffusion of solute in the liquid. Ripening can be accelerated by increasing stirring since this increases solute transport. By higher stirring speeds a change in morphology from dendritic to ripened rosettes containing liquid between the branches is promoted, increasing SDAS. As described by Flemming [6] and illustrated in Figure 2.

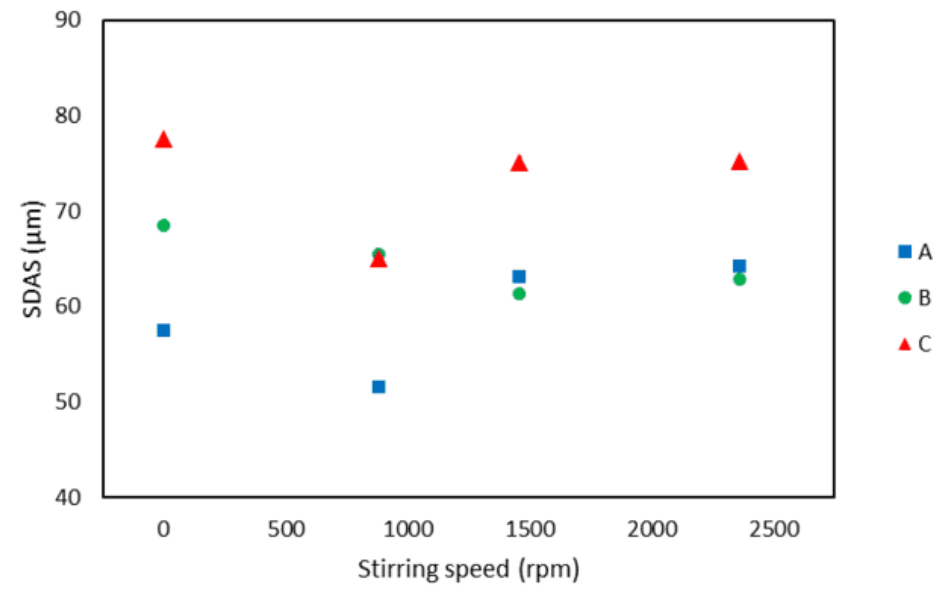

Figure 17. SDAS as a function of the degree of stirring.

Comments with respect to the distribution of silicon in the samples can be made after considering what is illustrated in Figure 18 by means of micrographs etched with Keller's reagent. Comparing samples $\mathrm{A}_{0}$ and $\mathrm{A}_{3}$, the effect of magnetic stirring on the distribution and shape of $\mathrm{Si}$ in the eutectic can be seen. In the case of sample $\mathrm{A}_{0}$ it is seen that the $\mathrm{Si}$ is found as thick and long plates with a homogeneous dispersion located between the $\alpha$-Al dendrites. In the case of sample $A_{3}$ the effect of vigorous stirring during the solidification becomes clear. The Si plates are located preferentially in the spaces that remain between the $\alpha$-Al rosettes. Although $\mathrm{Si}$ is still present as thick plates, they have smaller sizes, because the size of the spaces between the primary phase crystals decreases substantially with stirring, thereby limiting the growth of this phase. The lengths of the Si plates have been measured. It is observed that the size of the silicon plates decrease from $34.37 \pm 3,42$ and $27.71 \pm 3,12$ microns to $28.00 \pm 2,54$ and $26.51 \pm 2,47$ microns for alloys A and $\mathrm{C}$ without stirring and with maximum stirring respectively. 


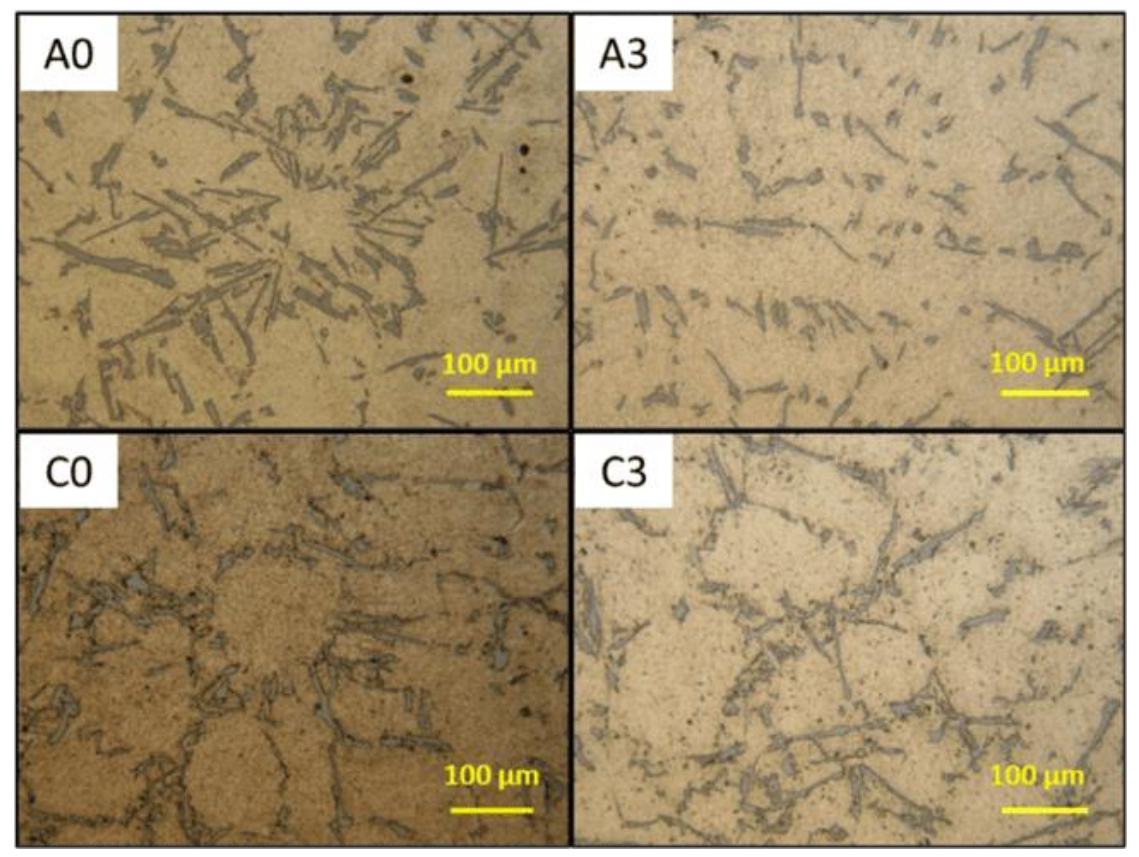

Figure18: Morphology and distribution of $\mathrm{Si}$ in the eutectic.

The above is in agreement with which was described previously with respect to the distribution of the $\mathrm{Si}$ and the mechanical properties, because the Si more finely dispersed in the matrix offers better mechanical characteristics than that distributed coarsely [7 - 9, 23]. Consequently, it would be expected that the sample subjected to fast stirring would have a greater yield strength and greater ductility at rupture [29, 30]. A similar effect is the one seen in the addition of $\mathrm{Sr}$ and Al-Ti-B (comparing $\mathrm{A}_{0}$ and $\mathrm{C}_{0}$ ).

Finally, in sample $\mathrm{C}_{3}$ there are zones in which the $\mathrm{Si}$ formed during the eutectic transformation has a thin-fiber morphology (Figure 19), which is an indication of the synergistic effect that is generated between magnetic stirring and the addition of modifying and refining elements. It has been shown significant improvements in terms of the hardness achieved, in addition to the decrease of the grain size and the morphology and distribution of the Si crystals in the eutectic have been seen. However, the research is open to obtain percentages of modifying and grain refining elements optimal for these types of materials.

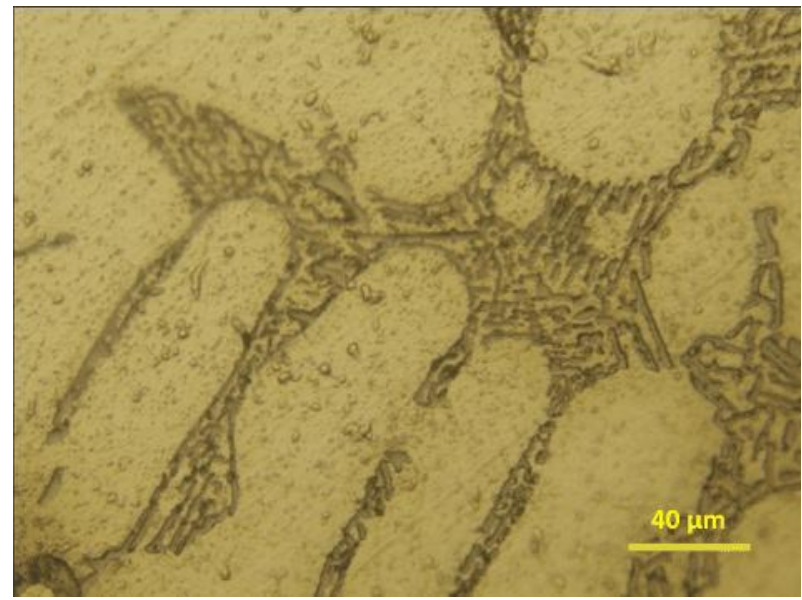

Figure 19. Completely modified C3 alloy zone. 


\section{CONCLUSIONS}

By studying the solidification of a original Al-Si-Mg alloy, modified with $\mathrm{Sr}$ and refined with Al-Ti-B, subjected to different degrees of magnetic stirring (in the semisolid state) it has been possible to evaluate the influence of this method for increasing the mechanical properties, and it has led to understanding the benefit of promoting the development of nondendritic structures of cast parts.

The magnetic stirring not only promotes dendritic fracture, but it also affects a distribution of $\mathrm{Si}$ in the eutectic, smaller in size, that favors the improvement of the material's mechanical behavior.

The presence of magnetic stirring during solidification, as well as the addition of alloying and refining elements to an A356 alloy, is beneficial to its mechanical properties (hardness); however, it is necessary to determine the optimum addition percentages of the latter with the purpose of not decreasing the mechanical properties due to eventually harmful second phase precipitates.

The shape factor (roundness) of the developed structures indicates that the closer to spheres are the developed crystals, the better their mechanical characteristics, and it is possible to approach unity, by incorporating modifiers, and grain refiners to the alloys and subject them to stirring during their solidification.

The shape, size, and distribution of the Si formed during the eutectic transformation has a sufficiently strong influence on the mechanical properties that a cast part of Al-Si alloys will deliver, with better performance shown by fine and homogeneously dispersed structures.

\section{ACKNOWLEDGEMENTS}

The authors acknowledge with thanks the financial support for this research to DICYT USACH.

Rodrigo Allende thanks the Comisión Nacional de Investigación Científica y Tecnológica, CONICYT-PFCHA/Doctorado Nacional/2017-21170167 for financing his graduate studies.

\section{REFERENCES}

[1] PORTER, D., EASTERLING K., SHERIF M., Phase Transformations in Metals and Alloys, 2 ed., Boca Ratón, CRC press, 2009.

[2] SHEWMON P., Transformations in metals, 1 ed. McGraw-Hill, Nueva York, 1969.

[3] BROWN J., Foseco non-ferrous foundryman's Handbook, 1 ed., Oxford, Butterworth-Heinemann, 1999.

[4] MOHAMMED M., OMAR M., SALLEH M., et al., "An overview of semi-solid metal processing", Australian Journal of Basic and Applied Sciences, v. 19, n. 8, pp. 369-373, Jan. 2014.

[5] MOHAMMED M., OMAR M., SALLEH M., et al."Semisolid metal processing techniques for nondendritic feedstock production", The Scientific World Journal, v. 2013, n. 1, pp. 1-16, Jul. 2013.

[6] FLEMINGS M., "Behavior of metal alloys in the semisolid state", Metallurgical transactions A, v. 22, n. 5, pp. 957-981, May. 1991.

[7] VOGEL A., DOHERTY R., "Proceedings of solidification and casting of metals conference", Metals Society, v. 192, n. 1, pp. 518-525, Jan. 1979.

[8] BUSTOS O., LEIVA R., SÁNCHEZ C., et al. "Evolución microestructural y propiedades reológicas de la aleación AA6063 fabricada mediante técnicas de procesado semisólido (SIMA y MHD)", Revista de metalurgia, v. 43, n. 3, pp. 165-180, May. 2007.

[9] AGRAWAL S., GHOSE A., CHAKRABARTY I, "Effect of rotary electromagnetic stirring during solidification of In-situ Al-TiB 2 composites", Materials \& Design, v. 113, n. 1, pp. 195-206, Jan. 2017.

[10] WILLERS B., ECKERT S., NIKRITYUK P., et al."Efficient melt stirring using pulse sequences of a rotating magnetic field: Part II. Application to solidification of Al-Si alloys", Metallurgical and Materials Transactions B, v. 39, n.2, pp. 304-316, Mar. 2008.

[11] NATORI K., UTSUNOMIYA H., TANAKA T., "Improvement in formability of semi-solid cast hypoeutectic Al-Si alloys by equal-channel angular pressing", Journal of Materials Processing Technology, v. 240, n 1, pp. 240-248, Feb. 2017.

[12] WEI H., XIA F., QIAN S., WANG M., "Effect of permanent magnetic stirring on the solidification microstructure and ingot quality of Al-Cu alloys", Journal of Materials Processing Technology, v. 240, n. 1, pp. 344-353, Feb. 2017.

[13] KUMAR S., SUMAN K., RAVINDRA K., et al."Microstructure, mechanical response and fractography of AZ91E/Al $\mathrm{O}_{3}(\mathrm{p})$ nano composite fabricated by semi solid stir casting method", Journal of Magnesi- 
um and Alloys, v. 5, n. 1, pp. 48-55, Mar. 2017.

[14] ZIMMERMANN G., PICKMANN C., HAMACHER M., et al."Fragmentation-driven grain refinement in directional solidification of AlCu10wt-\% alloy at low pulling speeds", Acta Materialia, v. 126, n. 1, pp. 236-250, Mar. 2017.

[15] WANG F., TZANAKIS I., ESKIN D., MI J., et al."In situ observation of ultrasonic cavitation-induced fragmentation of the primary crystals formed in Al alloys", Ultrasonics Sonochemistry, v. 39, n. 1, pp. 66-76, 2017.

[16] JOSEPH S., KUMAR S., "Role of Si modification on the compressive flow behavior of Al-Si based alloy", Materials Characterization, v. 110, n. 1, pp. 272-281, Dec. 2015.

[17] HEGDE S., PRABHU K., "Modification of eutectic silicon in Al-Si alloys", Journal of materials science, v. 43, n. 9, pp. 3009-3027, May. 2008.

[18] GUIGLIONDA G., POOLE W., "The role of damage on the deformation and fracture of Al-Si eutectic alloys", Materials Science and Engineering: A, v. 336, n. 1, pp. 159-169, Oct. 2006.

[19] TIMPEL M., WANDERKA N., SCHLESIGER R., et al."The role of strontium in modifying aluminiumsilicon alloys", Acta Materialia, v. 60, n. 9, pp. 3920-3928, May. 2012.

[20] JOSEPH S., KUMAR S., "A systematic investigation of fracture mechanisms in Al-Si based eutectic alloy—Effect of Si modification", Materials Science and Engineering: A, v. 588, n. 1, pp. 111-124, Dec. 2013.

[21] WANG Q., "Microstructural effects on the tensile and fracture behavior of aluminum casting alloys A356/357", Metallurgical and materials Transactions A, v. 34, n. 12, pp. 2887-2899, Dec. 2003.

[22] LIU W., XIAO W., XU C., et al."Synergistic effects of $G d$ and $\mathrm{Zr}$ on grain refinement and eutectic Si modification of Al-Si cast alloy", Materials Science and Engineering: A, v. 693, n. 1, pp. 93-100, May. 2017.

[23] HAGHAYEGHI R., DE PAULA L., ZOQUI E., "Comparison of Si Refinement Efficiency of Electromagnetic Stirring and Ultrasonic Treatment for a Hypereutectic Al-Si Alloy", Journal of Materials Engineering and Performance, v. 26, n. 4, pp. 1900-1907, Apr. 2017.

[24] ASTM E607-02, Standard Test Method for Atomic Emission Spectrometric Analysis Aluminum Alloys by the Point to Plane Technique Nitrogen Atmosphere, ASTM International, West Conshohocken, PA, 2002, www.astm.org.

[25] ASTM E3-11(2017), Standard Guide for Preparation of Metallographic Specimens, ASTM International, West Conshohocken, PA, 2017, www.astm.org.

[26] ASTM E10-17, Standard Test Method for Brinell Hardness of Metallic Materials, ASTM International, West Conshohocken, PA, 2017, www.astm.org.

[27] NAFISI S., GHOMASHCHI R., "Effect of stirring on solidification pattern and alloy distribution during semi-solid-metal casting", Materials Science and Engineering: A, v. 437, n. 2, pp. 388-395, Nov. 2006.

[28] ASTM E112-13, Standard Test Methods for Determining Average Grain Size, ASTM International, West Conshohocken, PA, 2013, www.astm.org

[29] IMMANUEL R., PANIGRAHI S., RACINEUX G., et al."Investigation on crashworthiness of ultrafine grained A356 sheets and validation of Hall-Petch relationship at high strain-rate deformation", Materials Science and Engineering: A, v. 701, n. 1, pp. 226-236, Jul. 2017.

[30] LEHTO P., REMES H., SAUKKONEN T., et al."Influence of grain size distribution on the Hall-Petch relationship of welded structural steel", Materials Science and Engineering: A, v. 592, n. 1, pp. 28-39, Jan. 2014.

\section{ORCID}

Oscar Arionel Bustos Castillo

Rodrigo Ignacio Allende Seco

Ricardo Rodrigo Leiva Íllanes

Christián Patricio Sánchez Villa https://orcid.org/0000-0001-7663-1528

https://orcid.org/0000-0002-2115-8160

https://orcid.org/0000-0002-8403-5264

https://orcid.org/0000-0001-5435-9201 